\title{
Capítulo II \\ La provincia y el nuevo método fenomenológico
}



Por las tardes, cuando durante la pausa del trabajo me siento con los campesinos en torno de la estufa o en la mesa junto del rincón donde está la imagen del Señor, casi nunca hablamos. En silencio fumamos nuestras pipas.

(Heidegger, 1963, p. 2)

En 1933 Heidegger decidió rechazar el ofrecimiento que le hizo la Universidad de Berlín para dar allí una cátedra, y prefirió quedarse en la provincia. En 1934, él mismo relató el episodio anterior en el brevísimo texto de tres páginas, “¿Por qué permanecemos en Provincia?”( 1963), donde describe un alto valle de la selva Negra habitado por campesinos y rodeado por árboles.

En una abrupta cuesta de un amplio y alto valle de la Selva Negra se levanta un pequeño refugio de esquiadores ("kleine Skihütte") a $1.150 \mathrm{~m}$. de altura sobre el nivel del mar. Su planta mide de 6 a $7 \mathrm{~m}$. El bajo techo recubre tres cuartos: la cocina, el dormitorio y un gabinete de estudio. En el estrecho fundo del valle y en la ladera opuesta, igualmente abrupta, yacen dispersos los cortijos de los campesinos, ampliamente emplazados, con el gran techo 


\section{Capítulo II- La provingia y el nuevo método fenomenológico}

que pende sobre ellos. Cuesta arriba se extienden las praderas y las dehesas hasta el bosque con sus viejos, enhiestos y oscuros abetos. Todo lo domina un claro de cielo soleado en cuyo resplandeciente espacio dos azores se elevan trazando círculos. (Heidegger, 1963 p. 1)

Este es para Heidegger su mundo de trabajo filosófico; desde allí se abre el ámbito de la realidad de la montaña. La marcha de un constante laborar permanece hundida en el acontecer del paisaje. Con vehemencia, Heidegger sostiene que el quehacer filosófico tiene una íntima relación con el trabajo de los campesinos:

\footnotetext{
Mi trabajo se asemeja al del joven campesino cuando sube la pendiente remolcando el trineo de montaña y luego, una vez bien cargado con leños de aya, lo dirige a su cortijo en peligroso descenso; al del pastor cuando con su andar lentamente meditabundo arrea su ganado pendiente arriba; al del campesino cuando en su cuarto dispone en forma adecuada las innumerables tablillas para su techo [...] Cuando en la profunda noche del invierno una bronca tormenta de nieve brama sacudiéndose en torno del albergue y oscurece y oculta todo, entonces es la hora propicia de la filosofía. Su preguntar debe entonces tornarse sencillo y esencial. La elaboración de cada pensamiento no puede ser sino ardua y severa. El esfuerzo por acuñar las palabras se parece a la resistencia de los enhiestos abetos contra la tormenta [...] La totalidad de mi trabajo está sostenida y guiada por el mundo de estas montañas y sus campesinos. (Heidegger, 1963, p. 2)
}

Para Heidegger, la tarea del pensar encuentra la hora propicia y su sustancia en la bronca de la tormenta. La búsqueda de la pregunta se erige como un instante tempestuoso cuando

La propia existencia se encuentra en su trabajo [...] Pero allí nunca puede estar a solas. Pues la auténtica soledad tiene la fuerza primigenia que no nos aísla, sino que arroja la existencia humana total en la extensa vecindad de todas las cosas. (Heidegger, 1963, pp. 1 y 2 )

El contenido crecer de los abetos, la gala luminosa y sencilla de los prados florecientes, el murmullo del arroyo de la montaña, la vasta noche del otoño en la austera sencillez de los llanos cubiertos de nieve acompañan al pensador cuando se enfrenta a lo más arduo de su oficio: hallar un camino para su pensar.

La inmediatez y originalidad de la comprensión de su propio pensar encuentra para Heidegger un lugar fundamental en la memoria campesina (bäuerliche Gedanken). Ella tiene la fidelidad (Treue) de lo sencillo, lo seguro y lo incesante. El lenguaje campesino, enérgico y lleno de imágenes, conserva su esencia y significado en las viejas palabras y sentencias. 
¿Qué alberga el espíritu de un auténtico lenguaje? Él custodia en su seno las sencillas pero fundamentales relaciones con Dios, con el mundo, con los hombres y las obras y ocupaciones de éstos. Lo que el espíritu del lenguaje alberga en sí es aquello sublime que impera a través de todo y desde donde cada cosa tiene su origen de modo tal que ella vale y fructifica. (Heidegger, 2000b, p. 59)

La pregunta fundamentada en la memoria campesina, en la sencillez y fidelidad del pensar-pensante, custodia y hace fructificar las esencias del mundo.

\section{$\S 12$. La tierra, la provincia y El camino en el campo}

En este punto se hace indispensable reflexionar sobre lo que Heidegger denominó tierra, entendiendo que:

De lo que dice esta palabra hay que eliminar tanto la representación de una masa material sedimentada en capas como la puramente astronómica, que la ve como un planeta. La Tierra es aquello en donde el surgimiento vuelve a dar acogida a todo lo que surge como tal. En eso que surge, la Tierra se presenta como aquello que acoge. (Heidegger, 2008b, p. 30)

Fiel, como siempre, al mundo de la provincia, Heidegger nos remite al mundo campesino cuando insiste con vehemencia que no es posible para el pensar-pensante comprender la verdad como desocultación, sin haber entendido antes que esa verdad yace oculta en la tierra que la acoge. Todo lo que surge y habrá de surgir ante la "nueva mirada" del ser-ahí yace oculto y protegido primero en ella.

¿Qué mejor metáfora de este concepto de tierra que el camino mismo? Allí habrá de tener lugar para Heidegger el grandioso y tan esperado "acontecimiento del ser"; en su ámbito lo sencillo habrá de erigirse como variante de comprensión del sentido del ser. De ahí que, en un primer momento, ese ser que habrá de acontecer como verdad, esté oculto, albergado y protegido en las entrañas de la tierra.

Los tilos, la colina, el roble, el banco de madera, las cortezas, los sembrados, los árboles, la cocina del hogar, el haz de leña, los surcos, las flores son tierra; lugar donde lo sencillo da acogida a todo lo que surge como totalidad (Das Einfach) en un dinamismo constante de sentido. Esta tierra, como matriz 
ontológica, como posibilidad fecunda del acontecimiento del ser, no es la tierra material y productiva que el pensamiento técnico concibe como recurso y utilidad, sino que es vista e interpretada desde el pensar-pensante,

\begin{abstract}
Se refugia en la masa y peso de la piedra, en la firmeza y flexibilidad de la madera, en la dureza y brillo del metal, en la luminosidad y oscuridad del color, en el timbre del sonido, en el poder nominal de la palabra [...] La Tierra es lo que hace emerger y da refugio. La Tierra es aquella no forzada, infatigable, sin obligación alguna. Sobre la Tierra y en ella, el hombre histórico funda su morada en el mundo [...] La Tierra solo se muestra como ella misma, abierta en su claridad, allí donde la preservan y la guardan como ésa esencialmente indescifrable que huye ante cualquier intento de apertura; dicho de otro modo, la Tierra se mantiene constantemente cerrada. (Heidegger, 2008b, p. 33)
\end{abstract}

La tierra ontológica se mantiene cerrada para cuidar y albergar el ser, que solo el pensar-pensante puede invocar y convocar al desocultamiento, al acontecimiento.

Todas las cosas de la Tierra, y ella misma en su totalidad, fluyen en una recíproca consonancia. Pero este fluir no es una manera de borrarse. Lo que aquí fluye es la corriente de la delimitación que reposa en sí misma y limita en su presencia a todo lo que se presenta. Así, cada una de las cosas que se cierran en sí mismas se desconocen en la misma medida. La Tierra es aquello que se cierra esencialmente en sí mismo. Traer aquí la Tierra significa llevarla a lo abierto, en tanto que aquello que se cierra a sí mismo. (Heidegger, 2008b, p. 34)

La ardua tarea del pensar implica también llevar la pregunta a lo abierto para develar su esencia. Lo sencillo en El camino en el campo es la tierra que se cierra, porque precisamente está preservando lo esencial. Por eso, con preocupación, Heidegger denuncia que:

\footnotetext{
Cuando el hombre no está en el orden del buen consejo del camino en el campo, trata en vano de sistematizar la tierra con sus planes. Amenaza el peligro que los hombres de hoy permanezcan sordos al lenguaje del camino en el campo. A sus oídos llega sólo el ruido de los aparatos que toman por la voz de Dios. El hombre se vuelve así, distraído y sin camino. Al distraído lo sencillo le parece uniforme. Lo uniforme harta. Los hastiados encuentran sólo lo indistinto. Lo sencillo escapó. Su quieta fuerza está agotada. Disminuye rápidamente, por cierto, el número de aquellos que conocen todavía lo sencillo como su propiedad adquirida. Pero los pocos serán en todas partes los que permanecerán. (Heidegger, 1983, trad.)
}

Solo pocos pensadores entienden que es precisamente en la tierra, en la cercanía de lo que llamamos "materia”, donde se oculta el Das Ein-fach, el 
sem-genus, el pacisco y el “ “ $\pi \alpha \xi$ ” del sentido. Entre los pocos que permanecerán se encuentra para Heidegger el pintor holandés Vincent Van Gogh.

Van Gogh pertenece al selecto grupo de los que todavía conocen el mundo de la provincia, los caminos del campo y lo sencillo como su propiedad adquirida. El pintor también visualiza que sin tal arraigo esencial a la tierra como matriz del ser, no es posible la desocultación de las esencias. El tema central de la obra pictórica de Van Gogh es el mundo de la provincia y el hombre que encuentra sus fundamentos en la cercanía material del mundo. Los comedores de patatas, El Sembrador, La Vendimia, Paisaje rural, Bosque, entre otros, son la existencia misma, la vida que se incrusta en lo sencillo para mostrarse como totalidad de surgimiento del sentido.

Van Gogh, al igual que Heidegger, no reflexiona nostálgicamente sobre el mundo campesino. Ambos exaltan la labor manual, el hacer, el vínculo indisoluble entre la mano y el espíritu. Los campesinos de Van Gogh son pobres, están sucios, recién llegan de un día marcado por el arduo trabajo; sobrevivieron, un día más, como el pensar genuino, a la bronca tormenta.

Esta mirada vinculante del campesino con el entorno es la que Heidegger resalta en su texto El origen de la obra de arte (2008), cuando centra la labor de su pensar en el cuadro de Van Gogh, Las botas de la labradora.

Las botas de la labradora pertenecen a la provincia, al camino en el campo. Heidegger exalta en ellas, como en toda la obra de Van Gogh, la intuición de lo sencillo como totalidad vinculante con la materialidad del mundo. $\mathrm{Al}$ respecto escribe:

\footnotetext{
En el cuero está estampada la humedad y el barro del suelo. Bajo las suelas se despliega toda la soledad del camino del campo cuando cae la tarde. En el zapato tiembla la callada llamada de la Tierra, su silencioso regalo del trigo maduro, su enigmática renuncia de sí misma en el yermo barbecho del campo invernal. (Heidegger, 2008b, p. 33)
}

$\mathrm{Al}$ igual que en los tilos, la colina, el roble, el banco de madera, las cortezas, los sembrados, los árboles, la cocina, la leña y las flores, en "Las botas de la labradora se desoculta una totalidad de sentido, un surgimiento completo de significado. Frente a la tierra, frente a los entes del camino, el ser-ahí se vincula directamente con el mundo. 


\section{Capítulo II - La provincia y el nuevo método fenomenológico}

El hombre histórico funda sobre la Tierra su morada en el mundo. Un mundo que no se funda sobre la base firme de la Tierra, un mundo aéreo y quimérico, no puede garantizar al hombre una morada estable. El hombre debe vivir con y entre las cosas, violentarlas, dejándoles ser lo que son. (Heidegger, 2008b, p. 36)

En El camino en el campo los entes reposan sobre la base firme de la tierra. También ellos, con su materia, con sus texturas, con sus colores, con sus aromas constituyen la facticidad del mundo. $Y$ al igual que el campesino, lo que el pensador necesita es la sencillez y la libertad del pensar; el tacto reservado respecto a su propio ser, ubicándose en un mundo que no es posterior sino previo a la experiencia, donde las cosas fructifican desde su origen. ${ }^{2}$

La provincia se erige entonces como el mundo comprendido previamente; el lugar donde los entes y el ser-ahí devienen intramundanos gracias al pensarpensante que, al igual que el trabajo del campo, ubica el sentido en el ámbito de la totalidad funcional de la tierra.

2 "Vimos que, para comprender el ente más próximo y todo ente que venga a nuestro encuentro y su entramado de útiles en su entramado de funcionalidad, necesitamos de una comprensión previa de la totalidad funcional, del entramado de significación, esto es, del mundo en general. A partir del mundo comprendido así, previamente, volvemos al ente intramundano. Porque, en tanto que existentes, ya hemos comprendido el mundo de antemano, podemos comprendernos y encontrarnos a nosotros mismos de forma constante en un modo específico por medio del ente que encontramos como intramundano. Porque, en tanto que existentes, ya hemos comprendido el mundo de antemano, podemos comprendernos y encontrarnos a nosotros mismos de forma constante en un modo específico por medio del ente que encontramos como intramundano. El zapatero no es el zapato, pero la herramienta del zapatero, perteneciente al entramado de útiles de su mundo circundante, es inteligible como tal herramienta sólo a partir del mundo que en cada caso pertenece a la constitución de existencia del Dasein como ser-en-el-mundo. El zapatero no es el zapato pero, al existir él es su mundo; su mundo es lo único que hace posible descubrir un entramado de útiles como intramundano y confrontarse con él. Son primariamente las cosas, no como tales, tomadas aisladas, sino como intramundanas, donde y a partir de las cuales nos encontramos a nosotros mismos. Por ello la cotidiana comprensión de sí del Dasein no depende tanto de la extensión y penetración de nuestro conocimiento de las cosas como de la inmediatez y originalidad del ser-en-el-mundo" (Heidegger, 2000c, pp. 214 y 215). 


\title{
$\S 13$. El pensar propio del "mundo de arriba"
}

Para desplegar su potencia propiciadora, el pensar-pensante debe recuperar su independencia alejándose del pensamiento certero de la ciudad y su falsa creencia corruptora. Por eso, la provincia es para Heidegger el "mundo de arriba", donde el pensar, vinculado a la tierra, es libre de manifestarse según su propia ley, fuera de las manos manipuladoras de la razón cosmopolita y homogenizante.

\begin{abstract}
El mundo de la ciudad ("Städtische Welt") está en peligro de sucumbir a una falsa creencia ("Irrglauben") corruptora. Una impertinencia muy ruidosa y muy activa y muy delicada parece, a menudo, preocuparse por el mundo y la existencia ("Dasein") del campesino. Pero con ello se niega precisamente lo que ahora sólo hace falta: mantener la distancia de la existencia campesina ("bäuerlichen Dasein”); abandonarla -ahora más que nunca- a su propia ley; ¡fuera las manos!; para no arrastrarla en una falsa habladuría de literatos sobre lo popular ("Volkstum") y amor a la tierra ("Bodenständigkeit"). El campesino ni quiere ni necesita en ningún caso esta exagerada amabilidad ciudadana. Lo que ciertamente necesita y quiere es el tacto reservado respecto a su propia ley ("Eigenständigkeit") y a su independencia. Pero muchos de los procedentes de la gran ciudad y de los transeúntes -y no en último término los esquiadores- se comportan a menudo en el pueblo o en la casa del campesino como si se "divirtieran" en sus salones de recreo de la gran ciudad. Tal ajetreo destruye en una noche más de lo que puede fomentar jamás un adecenamiento científico de varios decenios sobre lo popular ("Volkstum") y las costumbres y usos del pueblo ("Volkskunde").
\end{abstract}

Dejemos toda intimación condescendiente y todo falso culto de lo popular ("Volkstümelei"); aprendamos a tomar en serio allá arriba aquella existencia sencilla y dura. Sólo entonces nos podrá volver a decir algo. (Heidegger, 1963, p. 3)

Se debe tomar en serio la existencia sencilla y dura de "allá arriba" para que pueda volver a decir algo; tomar en serio el pensar-pensante, sencillo y duro. Solo si se deja de entender como diversión intelectual y se le otorga el respeto de regirse por su propia ley, el pensar tendrá la posibilidad de decir algo nuevo, mediante la reflexión sobre lo Ein-fach y el sem-genus, fundamentado en la totalidad y en la vinculación del ser-ahí con el surgir cercano del sentido. Nada distinto a lo que propone Van Gogh cuando desoculta la verdad de los entes desde la sencillez de la cercanía.

Al igual que el trabajo campesino, fundamentado en la importancia de lo que se erige como lo "a la mano", para Heidegger el lenguaje y el pensar-pensante son un traer a la presencia desde una actitud ontológica abierta, segura e incesante que es capaz de decir algo, precisamente por poder pensarse a cada instante 
desde la fecundidad de la cercanía. Para Heidegger, el nuevo preguntar de la ontología se torna sencillo, esencial. Pues la elaboración de cada pensamiento es el arduo preguntar que parte siempre del reto del comienzo. El esfuerzo por acuñar las palabras y por lograr que el pensar-pensante fructifique al margen del pensar científico se parece a la tormenta que arrecia contra la resistencia de los abetos que luchan por mantenerse; o también, como los girasoles de Van Gogh, que luchan por permanecer en el ser-siendo.

\footnotetext{
Y el trabajo filosófico no transcurre cual la apartada ocupación de un extravagante, sino que tiene una íntima relación con el trabajo de los campesinos [...] Los hombres de la ciudad se maravillan a menudo de este largo y monótono quedarse sólo entre los campesinos y las montañas. Sin embargo, esto no es ningún mero quedarse solo; pero sí soledad. En verdad en las grandes ciudades el hombre puede quedarse solo como apenas le es posible en cualquier otra parte. Pero allí nunca puede estar a solas. Pues la auténtica soledad tiene la fuerza primigenia ("ureigene Macht") que no nos aísla sino que arroja la existencia humana ("Dasein") total en la extensa vecindad de todas las cosas ("des Wessens aller Dinge").
}

Es posible convertirse fuera en una "celebridad" (Berühmtheit") en un santiamén mediante los periódicos y las revistas. Este es siempre, por cierto, el camino más seguro por el que el querer más auténtico sucumbe al malentendido y llega al olvido profunda y rápidamente. (Heidegger, 1963, p. 2)

Mediante el diálogo con el mundo de la provincia, Heidegger quiso colocar las principales motivaciones de su pensar en el plano del silencio, el vacío y la soledad creadora. Pues en el mundo de la provincia se esconden los fundamentos de su particular concepción del ser-ahí, vinculada con la cotidianidad del mundo campesino.

Antes de ubicar, en 1939, el pensar-pensante en El camino en el campo, Heidegger, en 1934, reflexiona desde la provincia sobre su propio trabajo filosófico; piensa su propio pensar y se enfrenta al problema de la decisión: ¿por qué permanecemos en provincia? ¿Por qué decidirse a pensar a la manera campesina? Porque es preciso abandonar los ámbitos de lo sobreentendido y volverse a enfrentar con la tormenta, con la pregunta que interroga por el sentido del ser, que yace en la cotidianidad fáctica de la tierra, de lo existente mismo: en el valor ontológico del hábito. 


\section{§ 24. El hábito}

La totalidad fenoménica de la apertura, desde la cual se significa todo aparecer fáctico apuntando a su aquí, constituye ella misma una peculiar trama de remisiones. El cómo de tal significar por remisiones aparece con el carácter de lo habitual en cada ocasión. La presencia, así como la manifestación de lo que aparece, son conocidas [...],y no en el sentido de que se tenga conocimiento de ello o acerca de ello, sino tal como uno conoce aquello en lo que uno mismo, de acuerdo con lo que se aparece, tiene experiencia. La cotidianidad domina a través de todos los distintos aspectos concretos de los nexos de remisiones. Todos nos arreglamos en cada ocasión, conocemos a otros, de igual manera que los demás le conocen a uno. Este conocer el mundo común es un conocer normal, medio, que se desarrolla en la cotidianidad y sirve siempre a ésta. Este hábito no es un modo de ver las cosas, sino el modo como ocurre lo existente mismo, el ser-en. (Heidegger, 1999b, p. 127)

No será el pensamiento de la ciudad el que propicie de nuevo la pregunta que interroga por el sentido del ser; tendrá que ser el pensar "de allá arriba", el que, al tornarse sencillo, esencial, arduo y severo vuelva a arrojar la existencia en la amplia vecindad de todas las cosas.

Sin embargo, en 1934, ubicado en la provincia, Heidegger no tiene todavía la palabra ni el lenguaje. Aún no se revela plenamente la metáfora del camino. No ha llegado a la distinción entre filosofía y pensar. Su pensar-pensante sigue siendo un encontrarse con el preguntar mismo en la bronca tormenta de la profundidad nocturna.

Lo que designamos ontológicamente con el término "encontrarse" es ónticamente lo más conocido y más cotidiano: el temple, el estado de ánimo [...] Y justo en medio de la más indiferente e inocente cotidianidad puede irrumpir el ser del "ser-ahí" como el nudo hecho de "que el "ser-ahî" es y ha de ser". Se hace patente el puro hecho de "que es"; el de dónde y el adónde permanecen en la oscuridad. La circunstancia de que no menos cotidianamente el "ser-ahî" no "caiga en la cuenta" de semejantes estados de ánimo, es decir, no "busque" que le "abran" lo que "abren", ni se preste a que lo coloquen ante lo "abierto" por ellos, no es una instancia en contra del fenómeno del afectivo "estado de abierto" del ser del "ahî" en su "que es", sino una prueba de él [...] El "que es y ha de ser" “abierto" en el "encontrarse" del "ser-ahí" no es ese "que es" que se expresa ontológico-categorialmente en la "efectividad" inherente al "ser ante los ojos". Ésta sólo se vuelve accesible en un fijar la vista en ella. El "que es" "abierto" en el "encontrarse" ha de concebirse, en cambio, como una determinación existenciaria de aquel ente que es en el modo del "ser en el mundo". (Heidegger, 2014, pp. 151, 152) 
El pensar-pensante en la provincia es aún un "qué es y ha de ser". Heidegger continúa buscando los fundamentos de lo sencillo, la ley interior que habrá de propiciar la pregunta que interrogue de nuevo por el sentido del ser.

\title{
§ 25. Proyección circular del ser-ahí
}

Ubicándose en la tierra, en el mundo de la provincia como el lugar de trabajo del pensador, para Heidegger es indispensable concebir un método que se adapte a la nueva dinámica del pensar y que pueda interpretarse como un camino que va y viene hacia el origen. No es casualidad que Heidegger conciba la exégesis del sentido del ser a partir de un método que finaliza donde comienza: en el ente intramundano.

\begin{abstract}
El mundo no es posterior, sino previo, en el estricto sentido de la palabra. Previo a lo que está develado y es entendido ya desde el comienzo en todo Dasein existente, antes de todo captar este o aquel ente; es previo en tanto en cuanto está siempre ya develado, ante nosotros. El mundo, en tanto que es lo ya previamente develado, es algo con lo que no nos ocupamos, algo que no aprehendemos, algo que, por el contrario, es tan comprensible de suyo que nos olvidamos totalmente de ello. El mundo es lo que está ya de antemano develado y es desde donde volvemos al ente con el que tenemos que tratar y con el que nos confrontamos. Podemos encontrar el ente intramundano sólo porque, en tanto que existentes, estamos ya en el mundo. Siempre comprendemos el mundo si nos mantenemos en un entramado de funcionalidad. Entendemos algo como el para-qué, el entramado formado por el para-qué, que designamos como el entramado de significatividad. (Heidegger, 2000c, p. 208)
\end{abstract}

Para Heidegger la analítica existenciaria en general debe explicitarse desde un proyectar circular que propicie el pensar desde el fenómeno de la propiedad y la totalidad: El camino en el campo que parte de la puerta del jardín y allí regresa.

\footnotetext{
¿No resulta así finalmente del todo patente que el problema ontológico fundamental que hemos desarrollado se mueve dentro de un círculo? Sin duda mostramos ya al hacer el análisis de la estructura del comprender en general que aquello que se censura con la inadecuada expresión "círculo" es inherente a la esencia distintiva del comprender mismo. A pesar de todo, tiene esta investigación que volver ahora expresamente sobre el "argumento del círculo", con vistas a aclarar la situación hermenéutica de los problemas ontológicofundamentales. (Heidegger, 2014, pp. 341 y 342)
} 
Esto aclara que la estructura ontológica del ente tiene su centro en el ser de la misma existencia, que obliga a una cierta comprensión de lo que ha de comprenderse. Heidegger habrá de llamarlo y entenderlo como hermenéutica de la facticidad.

\section{§ 15. El método fenomenológico de Heidegger}

Para entender el nuevo método fenomenológico, el ser-ahí necesita preguntarse por el nuevo sentido de la pregunta que interroga por el sentido del ser a partir de la existencia.

Lo que significa pensar determina el mandato de pensar. Pero el mandato que encomienda el pensamiento a nuestra esencia no es ninguna coacción. El mandato lleva nuestra esencia a lo libre, y lo hace en forma tan decisiva, que lo que nos llama al pensamiento, nos da por primera vez la libertad de lo libre, para que allí pueda habitar lo humanamente libre. (Heidegger, 2014, p. 209)

Es la libertad de la provincia cuyo mandato llega a ser tan fuerte y radical en la propuesta fenomenológica de Heidegger que incluso el método de la ontología tendrá que ser entendido desde las luces de la libertad del camino. Heidegger no quiere dejar el "es", el ser de los entes en manos de ningún saber racional que se justifique a partir del método científico moderno. De ahí que sea necesario pensar el método mismo de la ontología según un cierto orden, premisas y estructura. La búsqueda de la verdad no puede fundamentarse en la certeza instaurada por Descartes y adoptada por la mirada técnica del mundo.

\footnotetext{
Al igual que cualquier otro método científico, la fenomenología crece y se modifica en virtud de los progresos sobre los temas investigados que con su ayuda se efectúan. El método científico nunca es una técnica. Tan pronto como se convierte en una, decae de su propia esencia. (Heidegger, 2000c, p. 47)
}

Como se citó en la "Introducción", lejos del absolutismo epistemológico de la subjetividad, la hermenéutica de la facticidad es pensada desde los fundamentos ontológicos del pensar-pensante que explica el momento original cuando los entes se desocultan en su verdad original y logran fundar un mundo. Heidegger propone no una reducción de los actos de conciencia, como lo propuso Husserl, sino una reducción de los actos de la experiencia. Para Heidegger 
no puede haber una reflexión fenomenológica "despojada de mundo", como lo exige la Epojé de Husserl. Pues ahora el pensar, el conocimiento y la verdad son una forma del vivir mismo.

\begin{abstract}
El método de la ontología, es decir, el de la filosofía en general, se caracteriza por no tener nada en común con el método de ninguna otra ciencia, todas las cuales, en tanto que ciencias positivas, tratan del ente. Por otro lado, el análisis del carácter de verdad del ser muestra precisamente que también el ser asimismo se funda en un ente, a saber, el Dasein. Sólo hay ser si hay comprensión del ser, esto es, si existe el Dasein [...] La denominación terminológica para este carácter de la precedencia del ser respecto del ente es la expresión a priori, la aprioridad, el ser previo. Como a priori, el ser es anterior a los entes. Hasta hoy no se ha aclarado el sentido de este a priori, es decir, el sentido de lo anterior y su posibilidad. No se ha preguntado por qué las determinaciones del ser y el ser mismo deben tener este carácter de algo anterior y cómo es posible tal anterioridad. La anterioridad es una determinación temporal, pero una prioridad tal que no yace en el orden temporal del tiempo, que medimos con el reloj, sino una anterioridad que pertenece al "mundo trastocado (Heidegger, 2000c, pp. 45, 46)
\end{abstract}

Se trata de partir del ser para volver a él mismo mediante el recorrido de un camino. Este es el espíritu de la propuesta metodológica de Heidegger: caminar por la senda del pensar-pensante, trabajando con esfuerzo para llevar adelante el proyecto filosófico de Ser y tiempo (\$44): indagar sobre el fenómeno de la verdad mediante una ciencia que le sea propia con todas sus posibilidades y variantes.

Ser — no entes — solo lo "hay" hasta donde la verdad es. Y la verdad sólo es, hasta donde y mientras el "ser ahî" es. El ser y la verdad "son" igualmente originales. Lo que signifique: el ser "es", el ser, que debe distinguirse de todo ente, es cosa que únicamente puede preguntarse en concreto una vez aclarados el sentido del ser y el alcance de la comprensión del ser en general. Únicamente entonces cabe también exponer originalmente lo que es inherente al concepto de una ciencia del ser en cuanto tal, con sus posibilidades y variantes. Y al definir esta ciencia y su verdad, habrá que definir ontológicamente la ciencia como descubrimiento de los entes y su verdad.

Más aún no se ha dado la respuesta a la pregunta acerca del sentido del ser. (Heidegger, 2014, p. 251)

Entendido el pensar-pensante como un diálogo fecundo con el mundo, Heidegger expone un nuevo método fenomenológico para remontarnos "río arriba" y elaborar una ciencia del ser. Al proponer la destrucción, la reducción y la construcción como el camino de su nueva hermenéutica fenomenológica, Heidegger no está haciendo nada distinto a interpretar el sem-genus des-encubridor 
del trabajo de la provincia, trasladado a lo Ein-fach de la dura labor del pensar. Heidegger está pensando "lo sencillo". “Qué es, pues, de una vez, lo que permanece impensado tanto en el asunto propio de la filosofía como en el método que le es no menos propio?” (Heidegger, 1980, p. 141).

Lo sencillo permanece impensado. Desde él nos remontaremos hacia las vertientes originales del ser, mediante la destrucción, la reducción y la construcción de la nueva hermenéutica fenomenológica.

\footnotetext{
Destacar el ser de los entes y explicar el ser mismo es el problema de la ontología. Y el método de la ontología resulta cuestionable en sumo grado, mientras se pretenda pedir consejo acerca de él a las ontologías de la tradición histórica u otros intentos semejantes. Con el uso del término de ontología tampoco se habla en favor de una disciplina filosófica determinada que esté en relación con las restantes. No se trata en absoluto del problema de una disciplina previamente dada, sino a la inversa: es la necesidad objetiva de determinadas cuestiones y de la forma de tratarlas requerida por las "cosas mismas" de donde puede salir, si acaso, una disciplina [...] El título "fenomenología" expresa una máxima que puede formularse así: “ ¡a las cosas mismas!”, frente a todas las construcciones en el aire, a todos los descubrimientos casuales, frente a la adopción de conceptos sólo aparentemente rigurosos, frente a las cuestiones aparentes que se extienden con frecuencia a través de generaciones como "problemas". (Heidegger, 2014, pp. 37 y 38)
}

Luego de haber aclarado lo que significa para Heidegger el mundo de la provincia, quizá se aclare un poco más por qué su pensar se alejó radicalmente de la fenomenología de Husserl, entendida como ciencia estricta. Ahora el método de la ontología y el carácter de verdad del ser, antes de existir por sí mismos, deben fundamentarse como posibilidad en el a priori del tiempo.

\section{La destrucción fenomenológica de Heidegger}

La hermenéutica fenomenológica heideggeriana quiere volver a propiciar el pensar-pensante como un pensar desencubridor que emana desde la vastedad misma de la tierra, por eso se asemeja al trabajo campesino: arduo, severo, sencillo y esencial. A partir de su método, Heidegger quiere recordarle a la ontología que acuñar las palabras y las esencias requiere por parte del pensarpensante un esfuerzo y una sinceridad tan grandes como el que mantienen los abetos contra la tormenta.

Por eso la destrucción de la antigua tradición ontológica es fundamental, porque a partir de ella es posible volver a pensar el ser. La arrogancia racional 
y subjetiva de la historia de la ontología había dado por hecho la facilidad y el carácter obvio del preguntar certero. La razón, plena de sí misma, hizo de la pregunta por el sentido del ser un asunto obvio y desvinculó al hombre del mundo.

Por el contrario, en la provincia se desdeña el saber que ignora lo práctico y desliga al hombre de su acción en el mundo. La memoria campesina valoriza la relación vital del hombre con el útil y su carácter de "a la mano". Esto será lo que el pensar-pensante de Heidegger interpretará como la destrucción fenomenológica: ¡fuera las manos! y dejar el ente a su propia ley, y otorgarle así al pensar la capacidad de volver a interpretar el mundo sin los presupuestos teóricos anteriores, casi siempre inhibidores del Ein-fach y el sem-genus que involucran al ser-ahí con el mundo a partir del "surgir" y la "totalidad de sentido".

Por ello ocurre que toda exposición filosófica, incluso la más radical, que intenta comenzar desde el principio, está penetrada enteramente por conceptos tradicionales, $\mathrm{y}$, por consiguiente, por horizontes y perspectivas tradicionales que no podemos afirmar, como evidente de suyo, que hayan surgido auténtica y originariamente del ámbito del ser y de la comprensión del ser, que pretenden comprender. Por ello pertenece necesariamente a la interpretación conceptual del ser y de sus estructuras, esto es, a la construcción reductiva del ser, una destrucción, esto es, una deconstrucción [Abbau] crítica de los conceptos tradicionales, que, al comienzo, deben ser necesariamente empleados, que los deconstruya hasta las fuentes a partir de las que fueron creados. Sólo mediante la destrucción puede la ontología asegurarse fenomenológicamente la autenticidad de sus conceptos [...] La construcción de la filosofía es necesariamente destrucción, es decir, una deconstrucción de lo transmitido llevada a cabo mediante un regreso a la tradición, que no significa una negación de ella ni un prejuicio que considere que la tradición no es nada, sino, por el contrario, una apropiación positiva de ella. (Heidegger, 2000c, p. 48, 49)

Desde este primer momento del nuevo método fenomenológico, se hace urgente liberar los entes de la tradición metafísica, del pensamiento técnico que, desde la antigüedad, ha accedido al "es" a partir de la razón, la lógica, la 
representación y una interpretación del ser-ahí sesgada por el peso y la mirada unificadora de la tradición.

Pero la exégesis preparatoria de las estructuras fundamentales del "serahí" tomado en su forma de ser inmediata y "de término medio", que es también aquella en que es inmediatamente histórico, hará patente lo siguiente: el "ser ahî" no tiene sólo la propensión a "caer" en su mundo, en el cual es, e interpretarse reflejamente desde él; el "ser ahí" "cae", a una con ello, en su tradición más o menos expresamente tomada. Ésta le quita la dirección de sí mismo, el preguntar y elegir. Y no es lo último de lo que esto es válido aquella comprensión que tiene sus raíces en el más peculiar ser del "ser-ahí", la ontológica, y sus posibilidades de desarrollo.

La tradición, que así viene a imperar, hace inmediata y regularmente lo que "trasmite" tan poco accesible que más bien lo encubre [...] Si ha de lograrse en punto a la pregunta misma que interroga por el ser el "ver a través" de su peculiar historia, es menester ablandar la tradición endurecida y disolver las capas encubridoras producidas por ella. Es el problema que comprendemos como la destrucción del contenido tradicional de la ontología antigua, llevada a cabo siguiendo el hilo conductor de la pregunta que interroga por el ser, en busca de las experiencias originales en que se ganaron las primeras determinaciones del ser, directivas en adelante.

Este poner de manifiesto el origen de los conceptos ontológicos fundamentales, o investigación y exhibición de su "partida de nacimiento", no tiene nada que ver con una mala relativización del punto de vista ontológico. La destrucción tampoco tiene el sentido negativo de un sacudirse la tradición ontológica. Debe, a la inversa, acotarla dentro de sus posibilidades positivas, y esto quiere decir siempre dentro de sus límites, que les están dados fácticamente con la manera de hacer la pregunta en todo caso y la limitación del posible campo de la investigación impuesta de antemano por esta manera. (Heidegger, 2014, pp. 31, 32 y 33) 
Sumido en la tradición de la mirada técnica del mundo, el ser-ahí ha olvidado la pregunta: ¿'lo sencillo "es"? Ablandar la tradición, endurecida ante esta pregunta, variante de comprensión del sentido del ser, implica para Heidegger abandonar la ciudad, salirse de sus límites e insertar el pensar en la tierra, en la libertad propiciadora del mundo de la provincia.

\section{La reducción fenomenológica de Heidegger}

Mediante la reducción, como segundo paso del método fenomenológico, el pensar-pensante llama, invita, convoca, se enfoca, se centra en el ser del ente para mirarlo, contemplarlo y entenderlo por fuera del discurso de la metafísica, asumiendo una nueva mirada que habrá de interpretarlo por fuera del pensar técnico que históricamente ha tratado el "es" de los entes como simple unidad de propiedades, principios y causas primeras.

\footnotetext{
El ser debe ser comprendido y tematizado. El ser es en cada caso el ser de un ente y, por consiguiente, es accesible, de entrada, sólo partiendo de un ente. Por esta razón, la mirada fenomenológica debe dirigirse a un ente, pero de tal manera que el ser de ese ente pueda ponerse en descubierto y quepa llegar a una posible tematización. La comprensión del ser, esto es, la investigación ontológica, se dirige primero y necesariamente al ente, pero después se aleja, de algún modo, de ese ente y se vuelve al ser de ese ente. El componente fundamental del método fenomenológico, en el sentido de reconducción de la mirada inquisitiva desde el ente comprendido ingenuamente hasta el ser, lo designamos como reducción fenomenológica. (Heidegger, 2000c, pp. 46 y 47)
}

La reducción fenomenológica convoca al pensar-pensante a reducir la mirada hacia el objeto mismo, hacia su uso primero y su carácter de "a la mano", de una forma siempre nueva y renovada.

\footnotetext{
Sin embargo, el método de la ontología, en tanto que método, no es otra cosa que la serie de pasos que hay que dar para acceder al ser en cuanto tal, y para establecer sus estructuras. A este método de la ontología lo llamamos fenomenología [...] Lo que deberíamos hacer es recorrer otra vez el camino realizado, pero con expresa reflexión sobre él. Pero lo que es esencial, ante todo, para nosotros, es haber recorrido el camino una vez para, por una parte, aprender el asombro científico ante el enigma de las cosas, y, por otra, desvanecer todas las ilusiones que anidan de forma especialmente tenaz en la filosofía. (Heidegger, 2000c, p. 389, 390)
}

En El camino en el campo los tilos, la colina, el banco de madera son siempre "lo mismo" y, a la vez, "algo siempre nuevo" desde la mirada campesina que todavía tiene lugar para el asombro. En el trabajo del campesino, como en el 
del pensar genuino, se hace presente, de una forma siempre nueva, el sentido. En el mundo "de allá arriba" el pensar-pensante propicia la reducción fenomenológica porque mira siempre desde la nada original en la que se fortalecen el ser y el tiempo.

\footnotetext{
Para Husserl la reducción fenomenológica, que por primera vez elaboró de forma expresa en las Ideas para una fenomenología pura y una filosofía fenomenológica (1913), es el método de la reconducción de la mirada fenomenológica desde la actitud natural propia del hombre que vive en el mundo de las cosas y de las personas hasta la vida trascendental de la conciencia y sus vivencias noético-noemáticas, en las cuales se constituyen los objetos como correlatos de la conciencia. Para nosotros la reducción fenomenológica significa la reconducción de la mirada fenomenológica desde la comprensión, siempre concreta, de un ente hasta la comprensión del ser de ese ente (proyectada sobre el modo de su estar develado [Unverborgenheit]. (Heidegger, 2000c, p. 47)
}

La mirada heideggeriana consiste en contemplar el ente para proyectarlo, no hacia la soledad y el aislamiento de la conciencia, sino hacia el develamiento del mundo mismo donde se encuentra como ente y se valida como ente intramundano.

\footnotetext{
En el estrecho fondo del valle y en la ladera opuesta, igualmente abrupta, yacen dispersos los cortijos de los campesinos, ampliamente emplazados, con el gran techo que pende sobre ellos. Cuesta arriba se extienden las praderas y las dehesas hasta el bosque con sus viejos, enhiestos y oscuros abetos. Todo lo domina un claro cielo soleado en cuyo resplandeciente espacio dos azores se elevan trazando círculos.
}

Este es mi mundo de trabajo ("Arbeitswelt") visto con los ojos mirones del huésped o del veraneante. Yo mismo nunca miro realmente el paisaje. (Heidegger, 1963)

¿Qué tan reveladora puede resultar en este punto una afirmación así?: "Yo mismo nunca miro el paisaje" (Heidegger, 1963). Sencillamente, que quien ya transita por los caminos del pensar-pensante no mira el mundo con ojos vacíos de turista o visitante; no necesita pretender que se deleita con la superficialidad de los colores, los olores y las formas. Por el contrario, quien ya pertenece a la tierra asciende desde una compenetración artificial con el mundo contemplado, hacia la sensación ontológica de transformación continua, en la que el pensar-pensante percibe el devenir mismo de las esencias.

La pesadez, la dureza, el crecimiento, la luminosidad, los murmullos y las vibraciones de los entes se perciben, se intuyen, se anhelan y se presienten 
ya no con "los ojos mirones de huésped", sino con esa nueva mirada a la que nos convoca Heidegger con la reducción fenomenológica. Mirada que puede incluso prescindir del acto biológico de la vista, para acercarse al ente desde la fecundidad inicial de su nada, su vacío y su silencio.

\section{La construcción fenomenológica de Heidegger}

En esta misma dirección, la construcción fenomenológica también encuentra para Heidegger sus fundamentos en el mundo de la provincia. La construcción del sentido de los fenómenos encuentra un paralelo con el mundo campesino, donde se le otorga un sentido siempre nuevo a la relación del ser-ahí con el entorno.

Es en la Construcción fenomenológica donde Heidegger habrá de ubicar uno de los puntos centrales de su pensar: definir la verdad como desocultamiento. Y mediante del mundo de la provincia, la verdad no es otra cosa que el constante "surgimiento" de sentido, la $\dot{\alpha} \lambda \eta \dot{\theta} \theta \varepsilon ı \alpha$ permanente del ser, de todo aquello que constituye al mundo como lo que "es". Sentido y verdad que son "desocultados" por el poder fundador del "hacer", de un pensar-pensante que pregunta permanentemente por el origen e involucra al ser-ahí con las esencias del plexo de útiles que constituyen la cotidianidad de su mundo.

\footnotetext{
No existe la fenomenología y, si pudiera existir, nunca sería algo así como una técnica filosófica. En efecto, en la esencia de todo auténtico método, en tanto que camino para la revelación del objeto, se encuentra siempre el acomodarse a lo que mediante el propio método es revelado. Precisamente cuando un método es auténtico y proporciona el acceso a los objetos necesariamente se vuelve obsoleto en razón de los progresos realizados por él y de la creciente originalidad de la revelación que él permite. La única verdadera novedad en la ciencia y en la filosofía es sólo el preguntar auténtico y la lucha con las cosas que sirve a ese preguntar. (Heidegger, 2000c, p. 390)
}

Construcción que, para poder realizarse plenamente, requiere que el serahí esté volcado corpóreamente hacia lo sencillo como "totalidad en acto" del sentido, del fenómeno. Construcción imposible de pensarse sin lo Ein-fach, sin aquello que "de una vez", a partir de "una sola cara", involucra al ser-ahí existencialmente con la unidad plena del significado del sem-genus. Pues el acontecimiento de la verdad, el acontecimiento del sentido que tiene lugar a partir de la construcción fenomenológica, no es posible sin el sem-genus, sin el singullus, 
sin lo sencillo como intuición en acto de la totalidad de sentido que vincula al hombre con la tierra para luego desocultarle un mundo.

En este tercer momento del método fenomenológico, atendiendo libremente a la llamada del pensar-pensante, el "es", el ser de los entes, se desoculta, acontece como verdad, se abre, se muestra, se despliega a partir de una $\dot{\alpha} \lambda \eta \dot{\theta} \theta \varepsilon 1 \alpha$. La construcción que propone Heidegger nos coloca entonces frente a una nueva posibilidad de comprensión de la pregunta que interroga por el sentido del ser. Pregunta invocada y encontrada mediante el método inherente a los fenómenos, siempre y cuando estos sean concebidos e invocados mediante el pensar-pensante:

La forma de acceso y de interpretación tiene que elegirse más bien, de tal suerte, que este ente pueda mostrarse en sí mismo y por sí mismo. Y sin duda debe tal forma mostrar el ente tal como es "inmediata y regularmente" en su "cotidianidad" de "término medio". En ésta, deben ponerse de manifiesto, no estructuras accidentales y arbitrarias, sino estructuras esenciales que se corroboren determinantes del ser del "ser-ahí" fáctico. (Heidegger, 2014, p. 26, 27)

Para Heidegger la pregunta que interroga por el sentido del ser debe volver a pensarse desde lo Ein-fach, el "sem-genus", el instante, la "totalidad" y el "surgir" de un acto arduo y silenciosamente heroico; desde la pesadez de la montaña y la dureza de la roca primitiva que día a día enfrentan al hombre con la grandiosidad y la complejidad del mundo.

\footnotetext{
El ser no es tan accesible como el ente, no nos encontramos con facilidad frente a él, sino que, como se mostrará, debe siempre ser traído bajo la mirada en una libre proyección [Entwurf]. Designamos este proyectar un ente, dado previamente, sobre su ser y sus estructuras como la construcción fenomenológica. (Heidegger, 2000c, p. 47)
}

Por eso Heidegger cuestiona y niega el hecho de que solo a partir de la conciencia sea posible acercarse a las cosas mismas, y propone una hermenéutica fenomenológica, con miras a propiciar una $\dot{\alpha} \lambda \hat{n} \theta \varepsilon ı \alpha$, es decir, un desocultamiento de la experiencia del sentido del ser en la que el mundo se hace presente como posibilidad existencial.

No demasiado, sino demasiado poco "supone" la ontología del ser-ahí cuando parte de un yo sin mundo para darle luego un objeto y una relación a éste ontológicamente infundada. Demasiado corto alcanza la mirada cuando hace de "la vida" su problema y luego y ocasionalmente se toma en consideración también la muerte. Artificial y dogmáticamente 
mutilado está el objeto temático cuando se lo limita "ante todo" a un "sujeto teorético" para completarlo luego "por el lado práctico" en una "ética" adicional. Lo anterior bastará para aclarar el sentido existenciario de la situación hermenéutica de una analítica originaria del ser-ahí. (Heidegger, 2014, p. 343)

Mediante el método fenomenológico heideggeriano se quiere liberar el fenómeno de la mirada certera del pensamiento técnico. Primero, mediante una contundente destrucción de la historia de la ontología; luego, a través de la reducción de una nueva mirada, y finalmente, por medio de la construcción de un nuevo sentido en el que la verdad se presenta como desocultación del ser. "Estos tres componentes fundamentales del método fenomenológico, reducción, construcción y destrucción, se pertenecen mutuamente y deben ser fundamentados en su pertenencia mutua" (Heidegger, 2000c, p. 48).

Fiel a la dinámica ontológica del pensar-pensante que se fundamenta en el incesante comienzo, propiciador de la pregunta que interroga por el sentido del ser, el "es", la ontología tiene para Heidegger un fundamento óntico; es decir, que tiene que partir del ente.

\footnotetext{
La ontología tiene un fundamento óntico [...] De manera que la "primera tarea" dentro de la dilucidación del carácter científico de la ontología es "mostrar su fundamento óntico" y el carácter de éste fundar. La segunda es la caracterización del modo de conocimiento que se lleva a cabo en la ontología como ciencia del ser, esto quiere decir, "la elaboración de las estructuras metódicas de la distinción ontológico trascendental. (Heidegger, 2000c, p. 45)
}

Esta nueva estructura metodológica, no lineal ni deductiva, tiene como fin propiciar la ascensión del ser desde las profundidades del ente mediante el pensar-pensante de la esencia, para descender de nuevo al ente y propiciar el desocultamiento de una verdad que, lejos de ser certera o definitiva, le otorgará al ente la posibilidad de seguir concibiéndose como posibilidad en el tiempo y el espacio.

\section{$\S 16$. Lo sencillo en la vida de Heidegger}

La vinculación ontológica que Heidegger mantiene con la provincia no es una simple "pose tardía". La memoria campesina y su fidelidad a lo sencillo fueron desde siempre para el pensador un lugar vital. El padre de Heidegger, Friedrich Heidegger (1851-1924), fue tonelero y sacristán de la iglesia del pueblo: 
la iglesia de San Martín, llamada así en honor a San Martín de Tours (316-397) y a quien el pensador habrá de deberle su nombre. La madre, Johanna Kempf (1858-1927), era ama de casa.

Cuando nacieron sus hermanos, María y Fritz, la familia Heidegger veía pasar los días entre el trabajo del campo y las labores de la iglesia, que se encontraba a solo unos pasos de la casa. La condición modesta y sedentaria de la familia hizo que el trabajo del campo fuera fundamentalmente de subsistencia. "Heidegger reconoció durante toda su vida la humildad y pobreza de su origen social y se sintió siempre deudor de esa sencillez: "Procedo de un hogar pobre y sencillo", escribía en una carta a las autoridades civiles de Friburgo" (Cancelo, 1989, p. 157).

Para los Heidegger, la casa familiar es, de hecho, una prolongación de la vida del campo y de la vida de la Iglesia. En la familia son uno solo el trabajo de la mano y el espíritu. La "totalidad" de sentido "que surge de una vez" y que décadas más tarde el pensador habrá de relacionar con el fenómeno de lo sencillo, es una vivencia cotidiana. "En una sola cara", "de una sola vez", el hacer del campo y la reflexión trascendente constituyen para la familia Heidegger una "unidad indisoluble" de significado existencial. Hugo Ott (1992), en su texto Martin Heidegger, evidencia el vínculo profundo e indisoluble que desde sus primeros años, el primogénito de la familia tuvo con el mundo y el pensar de la provincia.

\footnotetext{
En la primera infancia los lugares de juego preferidos de Martin eran la granja, con sus múltiples rincones, y la escuela vecina con sus jardines. En una carta escrita a su primo Gustav Kempf, el mismo Heidegger escribe: “QQué dulce es habitar entre las cosas familiares de nuestros antepasados y experimentar en su memoria las palabras y obras de los ancestros!”. La carta muestra lo estrechamente ligados que están los recuerdos del viejo filósofo con una parte esencial de sus orígenes y su tierra natal". (p. 56)
}

La distancia que separa la casa y la iglesia es de aproximadamente unos 20 metros. Allí, como lo dejó consignado el mismo Heidegger en su escrito de 1956, "el misterio del campanario", la infancia y la Navidad se llenaban de alegría y de enigmas cuando los niños encendían las velas, los faroles, y se preparaban para subir a la torre a "decir la misa".

En las tempranas horas de la Navidad, hacia las tres y media, aproximadamente, de la madrugada, llegaban a la casa del sacristán los chicos encargados de tocar las campanas [...] 


\section{Capítulo II - La provincia y el nuevo método fenomenológico}

la emoción comenzaba en la casa misma del sacristán cuando los chicos, una vez saciados, encendían los faroles allí en el pasillo [...] Era entonces cuando entraban en acción las matracas para llamar a los oficios religiosos y a la oración [...] Aquella misteriosa fuga, en la que se entrelazaban las festividades de la Iglesia y sus Vigilias, el curso de las estaciones del año y las horas de cada día, las de la mañana, mediodía y las de la tarde, evolucionaba con tal ritmo que un tañido de campana penetraba permanentemente los jóvenes corazones, los sueños, las oraciones y los juegos. Es indudablemente ella la que porta en sí, protege, oculta y conserva uno de los misterios más encantadores, saludables y duraderos del campanario, y nos lo regala como algo que está constantemente en camino, se despliega y crece, irrepetible, hasta llegar al último tañido en el interior del amparo insondable del Ser. (Heidegger, 1989, pp. 154,157)

Estos recuerdos son el eco de las celebraciones más significativas para los niños, en especial para los de ascendencia suaba. Johanna Heidegger, por su parte, fiel a la tradición, preparaba con cuidado, cada año, la mesa con café, leche y pastas.

Durante semanas enteras, tal vez incluso, durante todo el año, los chicos gozaban pensando en aquella hora que habrían de transcurrir en la casa del sacristán. ¿Dónde podría estar oculto su encanto? Ciertamente no en aquello que "saboreaban" los chicos llegados a la casa tan de madrugada en la noche invernal. Algunos hubieran recibido cosas mejores en sus propias casas. Era, sin embargo, lo otro, lo singular y distinto de la casa, lo desacostumbrado del instante, la espera del sonar de las campanas, y la expectación de la misma fiesta. (Heidegger, 1989, p. 160)

En lo sencillo, que se hace presente en los faroles, la mesa servida, las campanas, las velas, la casa, los toneles y, por tanto, en los juegos, las actividades y el quehacer de cada día confluyen para Martin y los otros niños, el mundo del campo y el de la trascendencia. José Luis Cancelo, autor del prólogo de El misterio del campanario, evoca al respecto un interesante suceso:

A raíz del Concilio Vaticano I, la comunidad católica de Messkirch experimentó en sí misma una dolorosa escisión. Los que no aceptaban, entre otras cosas, la infalibilidad del Papa, pasaron a constituir la iglesia de los "viejos católicos". La Iglesia de San Martín pasó a manos de ellos. Los católicos tuvieron, entonces, que improvisar una Iglesia acondicionando diez graneros. Era una "iglesia de emergencia" dedicada al corazón de Jesús y en la cual fue bautizado Heidegger el día 29 de septiembre de 1889. En 1895 la comunidad de los "viejos católicos" había disminuido tanto que se vieron obligados a devolver la Iglesia de San Martin. El sacristán de los "viejos católicos", sin duda para encontrar un encuentro molesto con el sacristán católico Friedrich Heidegger, entregó, el primero de diciembre, las llaves de la Iglesia al mismo Heidegger, entonces un niño de seis años. A Heidegger le gustaba recordar, como una autoalabanza ingenua e inocente, este episodio: él, un niño de 
seis años, había recibido las llaves de la Iglesia. Aunque Heidegger recordara a veces el caso, no pretendía con ello insinuar simbolismos impertinentes, sino sencillamente, el agrado que encontraba en reconocerse como hijo del sacristán y el honor que experimentaba al sentirse portador de algo de las llaves de algo tan importante como la iglesia. (Cancelo, 1989, p. 157)

También la imagen personal que Heidegger construyó de sí mismo es una constante actualización de "lo siempre mismo" del mundo de la provincia. Autores como Hugo Ott, Walter Biemel y Luis Fernando Moreno Claros, entre otros, resaltan la forma como Heidegger trasladaba a la ciudad su vestimenta de campesino.

\footnotetext{
Según varios testimonios harto fiables, el propio Heidegger tenía mucho de campesino tanto en su aspecto exterior como en su manera de ser. Se cuenta que en cierta ocasión un famoso profesor impartió una conferencia, y que al final, comentó alborozado a sus colegas que en las primeras filas de oyentes se había sentado un "hombrecillo del campo" que parecía haber seguido con inusitada atención sus palabras: sin saberlo, se estaba refiriendo a Heidegger. El filósofo solía vestir trajes muy peculiares, cortados según el patrón del modelo regional, algo que resultaba chocante a los estudiantes, pues generalmente sólo las gentes sencillas se aferraban a ese tipo de indumentaria. Por lo demás, tanto apego a semejante manera de vestir denotaba un exagerado sentimiento provinciano y nacionalista. (Moreno, 2002, p. 44)
}

Lo sencillo de la vestimenta de Heidegger es una "totalidad de sentido" genuina al construirse no como discurso, y asimismo al representar el mundo cotidiano del ser-ahí. La reflexión sobre su traje no consiste en determinar si estamos hablando de telas baratas o modas poco lujosas. Lo sencillo aquí se refiere a lo que surge, al sem-genus, a lo que acontece como sentido en la totalidad ontológica del ser-ahí. La vestimenta de Heidegger interpreta el mundo campesino como metáfora del hombre volcado hacia el surgir del hacer, para quien cualquier tipo de ideología del yo es totalmente vanidosa e irrelevante.

\section{$\S$ 17. Una interpretación del pensar-pensante heideggeriano}

Un nuevo pensar, un nuevo método: una decisión radical que habría de generar todo tipo de seguidores y retractores. Heidegger y su pensar-pensante: una propuesta seguida por muchos y debatida por miles: la hermenéutica fenomenológica. Sin embargo, a los ojos de Hannah Arendt, quien de cerca conoció las luchas de Heidegger por huir de lo cosmopolita y fundar su pensar en el mundo de la provincia, no hay nada mejor que la metáfora de la madriguera 
del zorro (Arendt, 2006, p. 900) para ejemplificar lo que implica, para cualquier pensador "recién llegado", acceder a la "guarida" del "zorro Heidegger". Heidegger afirma muy orgulloso: "La gente dice que Heidegger es un zorro". Esta es la verdadera historia del zorro Heidegger:

Había una vez un zorro que carecía de tal modo de astucia que no sólo caía una y otra vez en las trampas, sino que no sabía distinguir entre una trampa y una no-trampa. El zorro poseía además otro defecto: tenía un problema con la piel, de tal modo que carecía de toda protección contra las inclemencias de la vida de zorro. Después de pasar toda su juventud en las trampas de otros y de que, por así decirlo, no le queda ni un trozo intacto de su piel, decidió retirarse totalmente del mundo de los zorros y emprendió la construcción de una zorrera. En su demencial ignorancia de las trampas y no-trampas y en su increíble experiencia con las trampas, se le ocurrió una idea del todo nueva e inaudita para cualquier zorro: se construyó una trampa como zorrera, se instaló en ella, la hizo pasar por una construcción normal (no por astucia, sino porque siempre había tomado las trampas de los otros por sus construcciones), pero decidió ser astuto a su manera y montar su trampa fabricada por él mismo, que sólo a él le iba bien, a la manera de una trampa para los otros. Esto demostraba, una vez más, su enorme desconocimiento del mundo de las trampas: pues nadie podía ver en su trampa porque él mismo estaba dentro, claro está. Esto lo fastidiaba; al fin y al cabo, es sabido que todos los zorros caen de vez en cuando en alguna trampa, a pesar de su astucia. ¿Por qué una trampa, fabricada además por el zorro más experto en trampas, no podía competir con las trampas de los hombres y de los cazadores? Por lo visto, porque la trampa no se identificaba claramente como tal. Así pues, el zorro tuvo la idea de adornar bellamente su trampa y de poner en todas partes señales que significaban con total nitidez lo siguiente: venid todos, que hay aquí una trampa, la trampa más bella del mundo. A partir de ese momento quedó clarísimo que ningún zorro caería sin querer en esta trampa. Pero muchos fueron. Porque la trampa, claro está, servía de construcción a nuestro zorro. Si alguien quería visitarlo en la construcción que era su hogar, debía entrar en su trampa. Cualquiera podía salir de ella tranquilamente, menos él mismo, desde luego. Estaba hecha literalmente a su medida. Sin embargo, el zorro que habitaba la trampa decía con orgullo: Tantos caen en mi trampa, me he convertido en el mejor de los zorros. Y había en ello 
algo cierto: Nadie conoce el mundo de las trampas mejor que quien lleva toda una vida instalado en una trampa. (Arendt, 2000, pp. 380-381)

El zorro en la tierra. El pensador en el mundo de la provincia. El pensarpensante en El camino en el campo. El reto de acceder al "mundo de arriba". E1 desafío de ir a las cosas mismas desde la hermenéutica fenomenológica. 
